Article

\title{
Personality Traits and Positive Resources of Workers for Sustainable Development: Is Emotional Intelligence a Mediator for Optimism and Hope?
}

\author{
Annamaria Di Fabio *, Letizia Palazzeschi, Ornella Bucci, Andrea Guazzini, Chiara Burgassi \\ and Eleonora Pesce \\ Department of Education and Psychology (Psychology Section), University of Florence, Via di San Salvi, 12, \\ Complesso di San Salvi, Padiglione 26, 50135 Firenze, Italy; letizia.palazzeschi@unifi.it (L.P.); \\ ornella.bucci@unifi.it (O.B.); andrea.guazzini@unifi.it (A.G.); chiaraburghi@gmail.com (C.B.); \\ eleonora.pesce92@gmail.com (E.P.) \\ * Correspondence: adifabio@psico.unifi.it
}

Received: 1 August 2018; Accepted: 4 September 2018; Published: 25 September 2018

\begin{abstract}
The 21st century is characterized by unpredictable and changing environments that require individuals and organizations to adapt to these challenges and prepare for continuous transitions in the work environment. Optimism and hope are positive resources that are key factors in navigating this post-modern work scenario. Emotional intelligence can be considered as another important variable in this context and furthermore, research has shown it can be increased through specific training. The aim of the present study is to examine the contribution of emotional intelligence in mediating the relationship between personality traits and both optimism and hope. The Big Five Questionnaire (BFQ), the Trait Emotional Intelligence Questionnaire (TEIQue-SF), the Life Orientation Test Revised (LOT-R), and the Hope Scale (HS) were administered to 201 Italian workers. Correlations among variables were calculated and mediation analyses were performed. The results showed that the relationships between personality traits and both optimism and hope are mediated by emotional intelligence. In particular, the contribution of emotional stability, agreeableness, and extraversion on optimism was mediated by emotional intelligence; the contribution of extraversion, emotional stability, and conscientiousness on hope was mediated by emotional intelligence. These results open new possibilities for research and interventions to enhance the personal resources of workers in the fluid scenario of the 21st century by promoting optimism and hope that are facilitated by emotional intelligence in the perspective of enhancing psychological aspects of sustainability and sustainable development.
\end{abstract}

Keywords: emotional intelligence; mediator; personality traits; optimism; hope; workers; psychology of sustainability and sustainable development

\section{Introduction}

In the postmodern era, which is characterized by continuous changes and transitions, it is important to foster individual resources [1-3], particularly in a primary prevention perspective that highlights the importance to early intervene building strengths that lead to positive outcomes for enhancing sustainability and sustainable development under a psychological point of view [4-9]. Within this framework, emotional intelligence represents a promising variable, because it can be increased through specific trainings $[10,11]$ differently from personality traits that can be considered substantially stable in the literature [12].

In the study of emotional intelligence construct, it is possible to substantially distinguish two different kinds of models [13]: ability-based models [14] and trait emotional intelligence 
models $[15,16]$. Ability-based models refer to cognitive abilities of emotional intelligence, as those necessary to elaborate emotional information [17], whereas trait emotional intelligence models refer to self-evaluation of one's own emotional and social skills $[15,16]$. A traditional trait emotional intelligence model is that by Bar-On [15] that refers to self-reported emotional intelligence in terms of perception of emotional and social competences that determine as individuals relate with themselves and with others and are able to face with environmental requests and pressures. A more recent and accredited trait emotional intelligence model is that by Petrides and Furnham [16], where trait emotional intelligence, called trait emotional self-efficacy, is considered as a constellation of self-perception and emotional correlated dispositions that primarily refers to the personality domain. The Petrides and Furnham [16] model can be considered as a more comprehensive model that includes aspects of emotional intelligence, such as emotion expression, emotion regulation, and self-motivation, which do not feature in the Bar-On model [15]. For this reason, in the present study, we refer to the trait emotional intelligence model [16].

In the literature, emotional intelligence is associated to positive resources, such as optimism [18-21] and hope [22,23]. Optimism was defined as a state of mind or attitude that is associated to expectations that are related to social or material future, which the evaluator feels as desirable for a personal advantage or pleasure [24]. Hope is a significant variable in the field of positive psychology [25]. It is defined as the perceived capability to motivate oneself via agency and derive pathways to desired goals [26]. Hope includes both agency and pathways dimensions. Agency refers to the energy to undertake one's own objectives and motivate oneself in times of difficulty while pathways refers to the perception to be able to derive the paths that may be traveled to achieve the desired objectives [26]. Having high emotional intelligence in terms of awareness of one's own emotions and emotions of others, expression of emotions, managing emotions, and the use of emotions in problem solving permits both to have a more optimistic view of the future [18-21] and use emotions for motivating themselves and to reach chosen objectives [22,23].

Regarding personality traits, studies carried out essentially on undergraduate students and that analyzed relationships of optimism showed in particular associations that are inverse with neuroticism and positive with extraversion [27-29]. Subsequent studies underlined, in addition to the relationships of optimism with neuroticism and extraversion, also positive associations with agreeableness [30-33]. Conscientiousness resulted instead especially linked to forms of academic optimism [34]. A more recent study [35] showed that optimism inversely correlated with neuroticism and positively with extraversion and agreeableness. With regards to relationships between personality traits and hope, positive associations were found between this construct and extraversion and conscientiousness, whereas an inverse association emerged with neuroticism [36,37].

With regards to relationships between emotional intelligence and optimism, emotional intelligence was considered as an antecedent of optimism [18], or, in some studies, emotional intelligence explained a percentage of incremental variance with respect to optimism in relation to different outcomes such as psychological adjustment [19] and resistance to stress [20]. In relation to hope, emotional intelligence was considered as a predictor [22,23]. It is possible to notice that the mediation role of emotional intelligence in the relationships between personality traits and both optimism and hope (and its dimensions) has not been studied in the literature, and thus it could deserve an exploration.

\section{Aim and Hypotheses}

On the basis of the theoretical framework previously delineated, the aim of the present study is to advance the research on emotional intelligence, examining its contribution in mediating the relationship between personality traits and both optimism and hope (extending the study also in terms of dimensions of hope) in Italian workers.

The following hypotheses were formulated: 
Hypothesis 1 (H1). The relationship between personality traits of emotional stability, agreeableness, and extraversion and optimism [30-33,35] will be mediated by emotional intelligence.

Hypothesis 2 (H2). The relationship between personality traits of extraversion, emotional stability, and conscientiousness and hope $[36,37]$ will be mediated by emotional intelligence.

Hypothesis 3 (H3). The relationship between personality traits of extraversion, emotional stability, and conscientiousness and agency dimension of hope $[36,37]$ will be mediated by emotional intelligence.

Hypothesis 4 (H4). The relationship between personality traits of extraversion and emotional stability, and conscientiousness and pathways dimension of hope [36,37] will be mediated by emotional intelligence.

\section{Method}

\subsection{Participants}

Participants were 201 Italian workers from public organizations in the Tuscany region (female: $69 \%$; males: $31 \%$; mean age $=45.50$ years, $S D=9.34$ ). They were predominantly White Italians. Education levels consisted of less than high school (17.41\%), high school graduate $(41.79 \%)$, and college degree $(40.80 \%)$. Participants voluntarily completed the questionnaire with waste being in the order of $10 \%$.

\subsection{Measures}

Big Five Questionnaire (BFQ). The Big Five Questionnaire (BFQ) [38] was adopted to detect personality traits. The BFQ contains 132 items with a response format on a 5-point Likert scale ranging from $1=$ Absolutely false to $5=$ Absolutely true. The questionnaire individuates five principal personality traits with the following Cronbach's alpha values: 0.84 for extraversion (example of item: "I am often completely absorbed in my commitments and activities"), 0.73 for agreeableness (example of item: "I hold in high regard the point of view of my colleagues"), 0.81 for conscientiousness (example of item: "I usually take care of everything in the smallest details"); 0.90 for emotional stability (example of item: "I have no trouble controlling my feelings"); and, 0.75 for openness (example of item: "I like to keep myself informed of topics that are far from my areas of expertise"). Concerning convergent validity, the BFQ factors showed positive correlations with the NEO Personality Inventory Revised (NEO-PI-R) [12] and with the Stait-Trait Anxiety Inventory, Form x (STAI) [39] whereas with regard to divergent validity, the BFQ factors did not correlate with the Wechsler Adult Intelligence Scale (WAIS) [40].

Trait Emotional Intelligence Questionnaire Short Form (TEIQue-SF) [41]. To evaluate trait emotional intelligence, the Trait Emotional Intelligence Questionnaire Short Form in the Italian version by Di Fabio and Palazzeschi [42] was adopted. It is composed by 30 items drawn from the 153 item TEIQue with a response format on a seven-point Likert scale $(1=$ Completely disagree to $7=$ Completely agree $)$. Examples of items are: "Expressing my emotions with words is not a problem for me"; "I often find it difficult to see things from another person's viewpoint". The Cronbach's alpha was 0.81 . Correlations of the TEIQue-SF with Bar-On Emotional Quotient Inventory (Bar-On EQ-i) [15] and the Mayer Salovey Caruso Emotional Intelligence Test (MSCEIT) [43] underlined a good construct validity.

Life Orientation Test-revised (LOT-r). To evaluate optimism, the Life Orientation Test-revised [24] in the Italian version by Giannini, Schuldberg, Di Fabio, and Gargaro [44] was adopted. This scale consists of 10 items on a five-point Likert scale ranging from $0=$ Strongly disagree to $4=$ Strongly agree. Examples of items are: "In uncertain times, I usually expect the best"; "Overall, I expect more good things to happen to me than bad". The Italian version of the LOT-r has a one-dimensional factorial structure. The Cronbach's alpha coefficient was 0.81 . Positive correlations between the Italian version of the LOT-r and the Rosenberg Self-Esteem Scale [45] showed a good concurrent validity. 
Hope Scale (HS). To evaluate hope, we adopted the Hope Scale $[26,46]$ in the Italian version by Di Fabio (2014). The scale is composed of 12 items with an eight-point Likert scale response format from $1=$ Definitely False to $8=$ Definitely True. The scale is bi-dimensional and permits to detect two dimensions: Pathways (example of item "I can think of many ways to get out of a jam") and Agency (example of item "I energetically pursue my goals"). Regarding reliability, the Cronbach's alpha coefficients were 0.87 for the total score, 0.88 for Agency, and 0.86 for Patway. Correlations of the Italian version of the Hope Scale with the Student Perceived Employability Scale (SPES) [47] and the Career Decision Self Efficacy Scale Short Form (CDSES-SF) [48] underlined an adequate concurrent validity of the scale.

\subsection{Procedure and Data Analysis}

The study assured respondents anonymity and confidentiality. The questionnaire included a statement regarding the personal data treatment, in accordance with the Italian privacy law (Law Decree DL-196/2003). The workers authorized and approved the use of anonymous/collective data for possible future scientific publications. Because the data was collected anonymously and the research investigated psycho-social variables not adopting a medical perspective, ethical approval was not sought. The participants voluntarily filled the questionnaires. The instruments were administered to groups of respondents by trained psychologists during their job. The order of administration was counterbalanced to control the effect of presentation. Pearson's $r$ correlations among variables were calculated to test the possibility of performing a mediation analysis. We included the variables that were associated on the basis of the literature, and among them we comprised those that correlated more than 0.30. Analyses of mediation [49] propose that evidence for mediation is found by examining the joint significance of the path from the independent variable (IV) to the mediator $(\alpha)$ and the path from the mediator to the outcome ( $\beta$ ) after accounting for the effects of the IV. Evidence for mediation requires a significant association between the IV and change in the mediator $(\alpha)$, and either a significant main effect of changes in the mediator on changes in the outcome $(\beta)$ or a significant effect of the interaction between the IV and change in the mediator on changes in the outcome $\left(\beta^{\prime}\right)$. Specifically, we used a regression based model that was developed for the analysis of mediation effects [50]. Finally, the analysis reported the effect sizes for the mediator, i.e., the proportion of the effect of the IV that was accounted for by the mediator.

\section{Results}

Correlations were reported in Table 1.

Table 1. Means, Standard Deviations, and Correlations between Personality traits (BFQ), Optimism (LOT-r), Hope (HS), Emotional Intelligence.

\begin{tabular}{|c|c|c|c|c|c|c|c|c|c|c|}
\hline & 1 & 2 & 3 & 4 & 5 & 6 & 7 & 8 & 9 & 10 \\
\hline 1. BFQ E & - & & & & & & & & & \\
\hline 2. BFQ A & $0.23 * *$ & - & & & & & & & & \\
\hline 3. BFQ C & $0.19 * *$ & $0.23 * *$ & - & & & & & & & \\
\hline 4. BFQ ES & $0.23 * *$ & $0.32 * *$ & 0.09 & - & & & & & & \\
\hline 5. BFQ O & $0.41 * *$ & $0.48^{* *}$ & 0.05 & $0.26 * *$ & - & & & & & \\
\hline 6. LOT-r & $0.38^{* *}$ & $0.41 * *$ & 0.11 & $0.49 * *$ & $0.34 * *$ & - & & & & \\
\hline 7. HS & $0.47^{* *}$ & $0.30 * *$ & $0.32 * *$ & $0.40 * *$ & $0.34 * *$ & $0.51 * *$ & - & & & \\
\hline 8. HS Agency & $0.44 * *$ & $0.30 * *$ & $0.38 * *$ & $0.38 * *$ & $0.29 * *$ & $0.47 * *$ & $0.89 * *$ & - & & \\
\hline $\begin{array}{l}\text { 9. HS } \\
\text { Pathways }\end{array}$ & $0.41 * *$ & $0.24 * *$ & $0.21 * *$ & $0.34^{* *}$ & $0.32 * *$ & $0.45^{* *}$ & $0.91 * *$ & $0.63 * *$ & - & \\
\hline 10. TEIQue-SF & $0.44 * *$ & $0.45^{* *}$ & $0.30 * *$ & $0.52 * *$ & $0.41 * *$ & $0.62 * *$ & $0.58 * *$ & $0.58^{* *}$ & $0.47^{* *}$ & - \\
\hline$M$ & 73.62 & 84.38 & 80.34 & 72.45 & 83.13 & 20.28 & 45.34 & 23.00 & 22.35 & 150.18 \\
\hline$S D$ & 8.80 & 8.91 & 9.91 & 13.16 & 9.35 & 3.97 & 8.03 & 4.28 & 4.63 & 20.01 \\
\hline$\alpha$ & 0.80 & 0.73 & 0.78 & 0.87 & 0.84 & 0.79 & 0.82 & 0.76 & 0.78 & 0.84 \\
\hline
\end{tabular}


The mediation analysis with optimism as dependent variable was reported below.

In line with our hypothesis, emotional stability exerted a significant positive indirect effect on optimism through emotional intelligence $(\beta=0.08, p<0.001$ ). The biased-corrected bootstrapping confidence interval for the indirect effect did not contain zero, $95 \% \mathrm{CI}[0.02,0.10]$. After controlling for emotional intelligence, there was a significant positive direct effect of emotional stability on optimism, $\beta=0.07, p<0.001$. The effect of the mediator was significant, with an effect size of $20 \%$ (i.e., $r^{2}=0.20$ ). The results are illustrated in Figure 1.

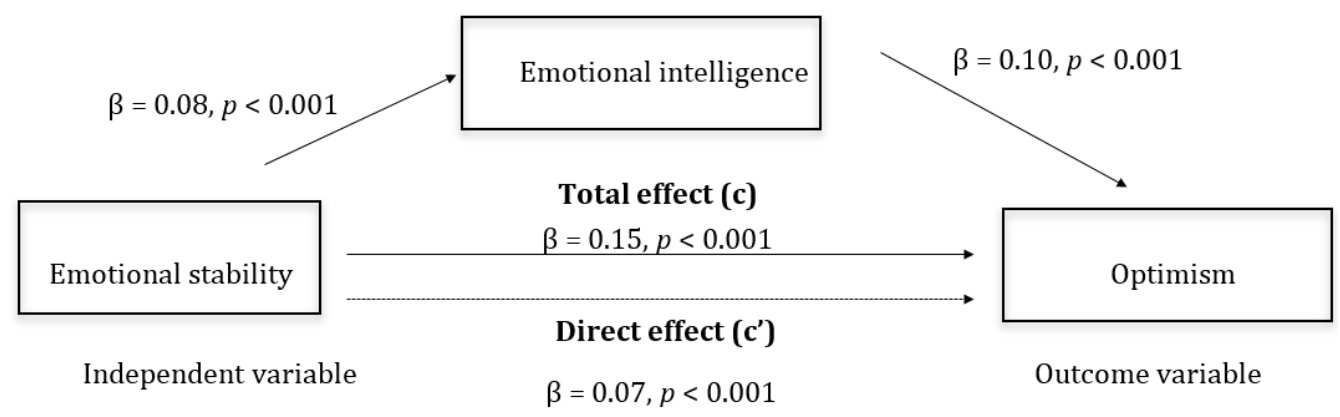

Figure 1. Relationship between emotional stability and optimism with emotional intelligence as mediator. $R^{2}$ Mediator Effect Size $=0.20$.

Agreeableness exerted a significant positive indirect effect on optimism through emotional intelligence $(\beta=0.11, p<0.001)$. The biased-corrected bootstrapping confidence interval for the indirect effect did not contain zero, $95 \%$ CI [0.08, 0.15]. After controlling for emotional intelligence, there was a significant positive direct effect of agreeableness on optimism, $\beta=0.07, p<0.001$. The effect of the mediator was significant, with an effect size of $15 \%$. The results are illustrated in Figure 2.

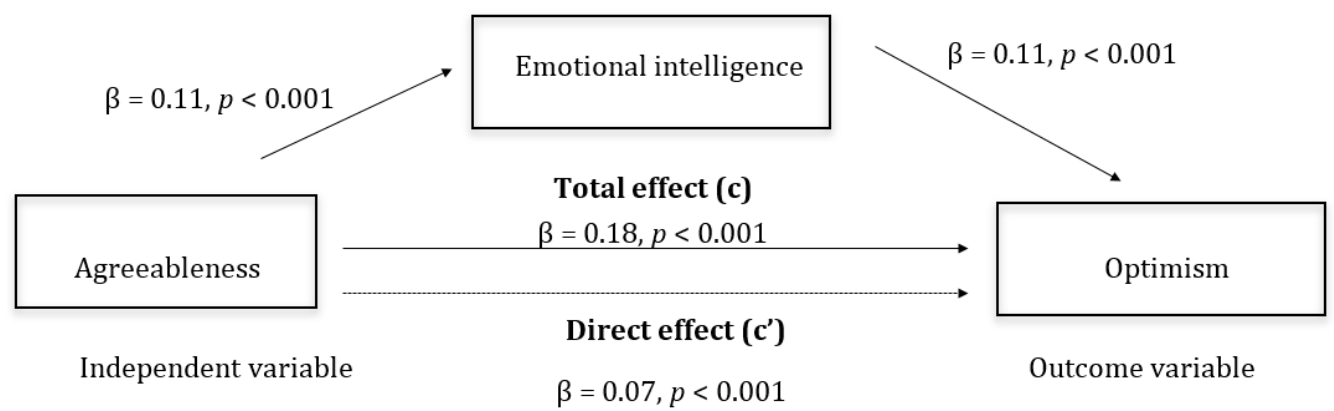

Figure 2. Relationship between agreeableness and optimism with emotional intelligence as mediator. $R^{2}$ Mediator Effect Size $=0.15$.

Extraversion exerted a significant positive indirect effect on optimism through emotional intelligence $(\beta=0.11, p<0.001)$. The biased-corrected bootstrapping confidence interval for the indirect effect did not contain zero, $95 \%$ CI $[0.07,0.16]$. After controlling for emotional intelligence, there was a significant positive direct effect of extraversion on optimism, $\beta=0.06, p<0.001$. The effect of the mediator was significant, with an effect size of $13 \%$. The results are illustrated in Figure 3.

The mediation analysis with hope as the dependent variable was reported below.

In line with our hypothesis, extraversion exerted a significant positive indirect effect on hope through emotional intelligence $(\beta=0.18, p<0.001)$. The biased-corrected bootstrapping confidence interval for the indirect effect did not contain zero, $95 \%$ CI $[0.12,0.28]$. After controlling for emotional intelligence, there was a significant positive direct effect of extraversion on hope, $\beta=0.35, p<0.001$. The effect of the mediator was significant with an effect size of $16 \%$. The results are illustrated in Figure 4. 


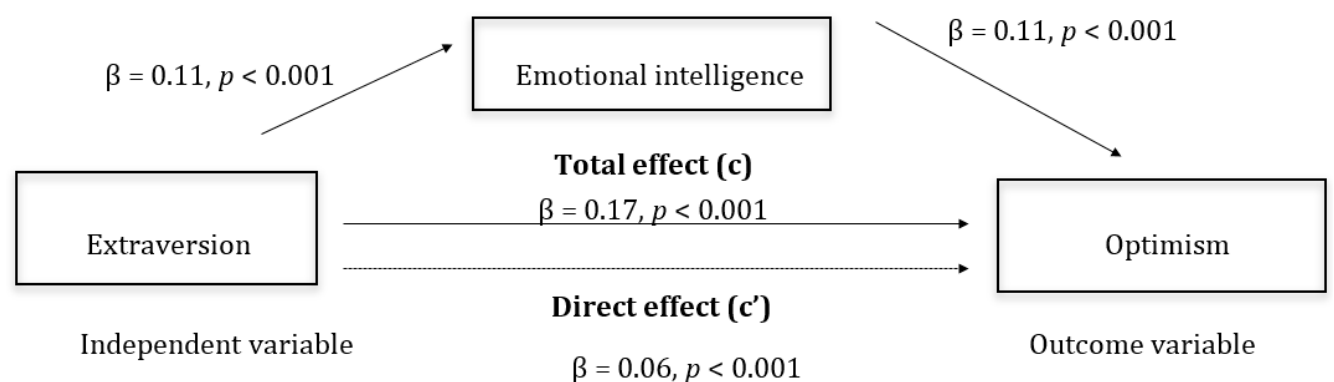

Figure 3. Relationship between extraversion and optimism with emotional intelligence as mediator. $R^{2}$ Mediator Effect Size $=0.13$.

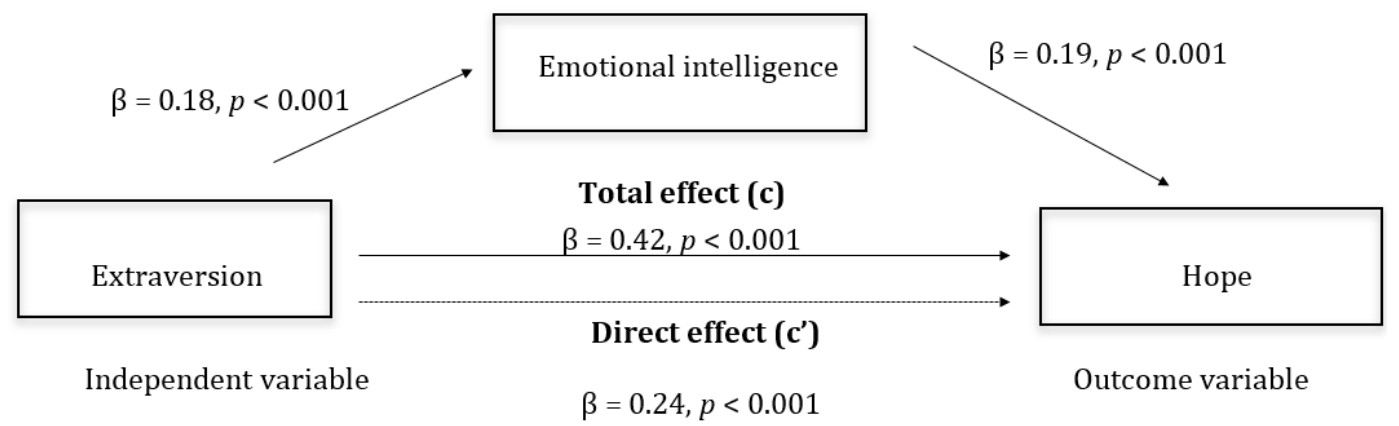

Figure 4. Relationship between extraversion and hope with emotional intelligence as mediator. $R^{2}$ Mediator Effect Size $=0.16$.

Emotional stability exerted a significant positive indirect effect on hope through emotional intelligence $(\beta=0.16, p<0.001)$. The biased-corrected bootstrapping confidence interval for the indirect effect did not contain zero, 95\% CI [0.11, 0.23]. After controlling for emotional intelligence, there was a significant positive direct effect of emotional stability on hope, $\beta=0.08, p<0.001$. The effect of the mediator was significant, with an effect size of $14 \%$. The results are illustrated in Figure 5 .

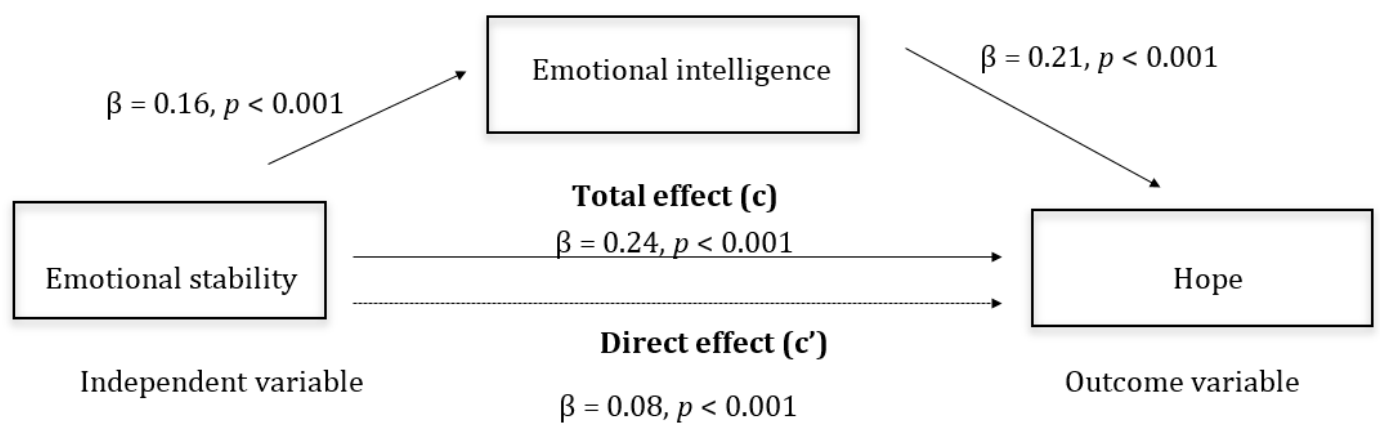

Figure 5. Relationship between emotional stability and hope with emotional intelligence as mediator. $R^{2}$ Mediator Effect Size $=0.14$.

Conscientiousness exerted a significant positive indirect effect on hope through emotional intelligence $(\beta=0.13, p<0.001)$. The biased-corrected bootstrapping confidence interval for the indirect effect did not contain zero, $95 \%$ CI $[0.07,0.20]$. After controlling for emotional intelligence, there was a significant positive direct effect of conscientiousness on hope, $\beta=0.13, p<0.001$. The effect of the mediator was significant, with an effect size of $8 \%$. The results are illustrated in Figure 6.

The mediation analysis with agency dimension of hope as the dependent variable was reported below.

In line with our hypothesis, extraversion exerted a significant positive indirect effect on agency dimension of hope through emotional intelligence $(\beta=0.10, p<0.001)$. The biased-corrected 
bootstrapping confidence interval for the indirect effect did not contain zero, 95\% CI [0.06, 0.15]. After controlling for emotional intelligence, there was a significant positive direct effect of extraversion on agency dimension of hope, $\beta=0.11, p<0.001$. The effect of the mediator was significant with an effect size of $15 \%$. The results are illustrated in Figure 7.

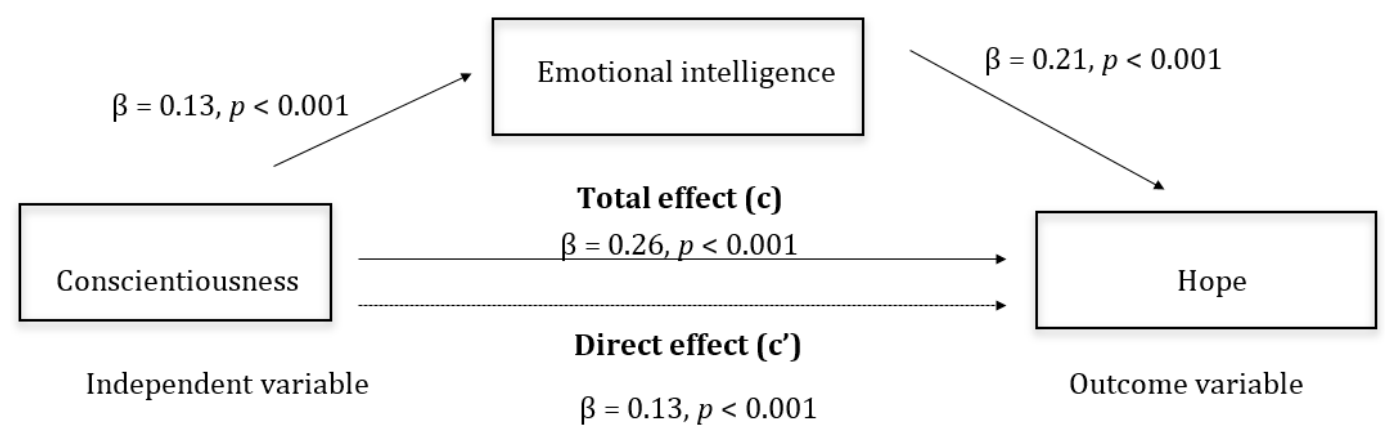

Figure 6. Relationship between conscientiousness and hope with emotional intelligence as mediator. $R^{2}$ Mediator Effect Size $=0.08$.

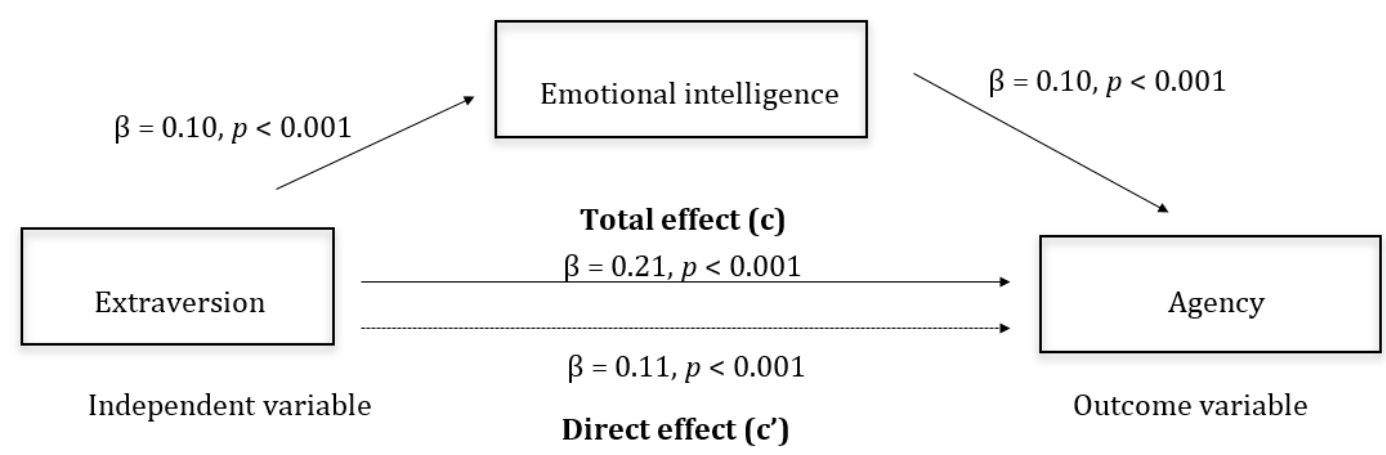

Figure 7. Relationship between extraversion and agency dimension of hope with emotional intelligence as mediator. $R^{2}$ Mediator Effect Size $=0.15$.

Emotional stability exerted a significant positive indirect effect on agency dimension of hope through emotional intelligence $(\beta=0.09, p<0.001)$. The biased-corrected bootstrapping confidence interval for the indirect effect did not contain zero, $95 \%$ CI [0.06, 0.13]. After controlling for emotional intelligence, there was a significant positive direct effect of emotional stability on the agency dimension of hope, $\beta=0.03, p<0.05$. The effect of the mediator was significant with an effect size of $13 \%$. The results are illustrated in Figure 8.

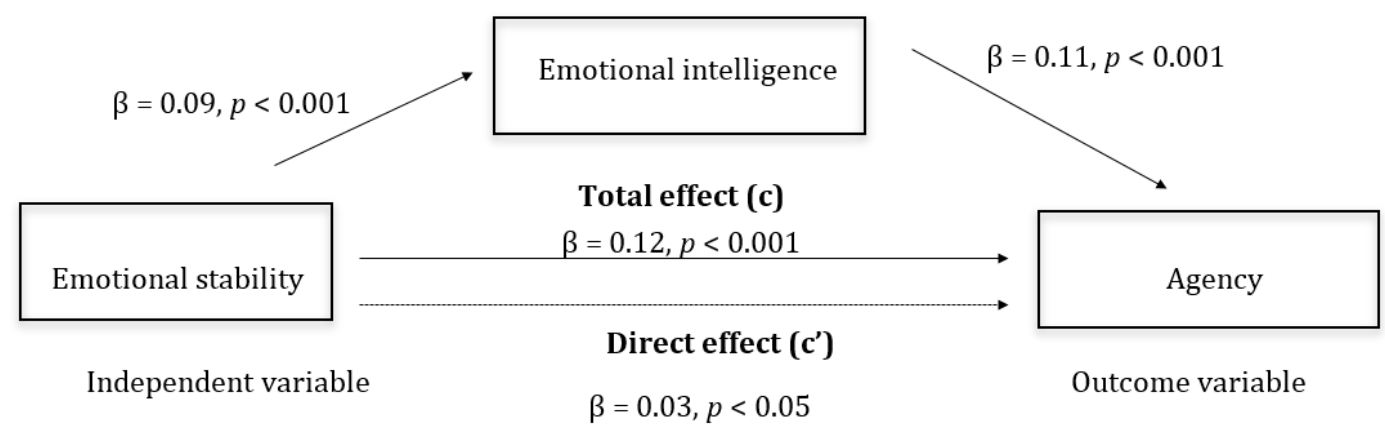

Figure 8. Relationship between emotional stability and agency dimension of hope with emotional intelligence as mediator. $R^{2}$ Mediator Effect Size $=0.13$.

Conscientiousness exerted a significant positive indirect effect on agency dimension of hope through emotional intelligence $(\beta=0.06, p<0.001)$. The biased-corrected bootstrapping confidence 
interval for the indirect effect did not contain zero, $95 \%$ CI $[0.04,0.10]$. After controlling for emotional intelligence, there was a significant positive direct effect of conscientiousness on the agency dimension of hope, $\beta=0.10, p<0.001$. The effect of the mediator was significant, with an effect size of $10 \%$. The results are illustrated in Figure 9.

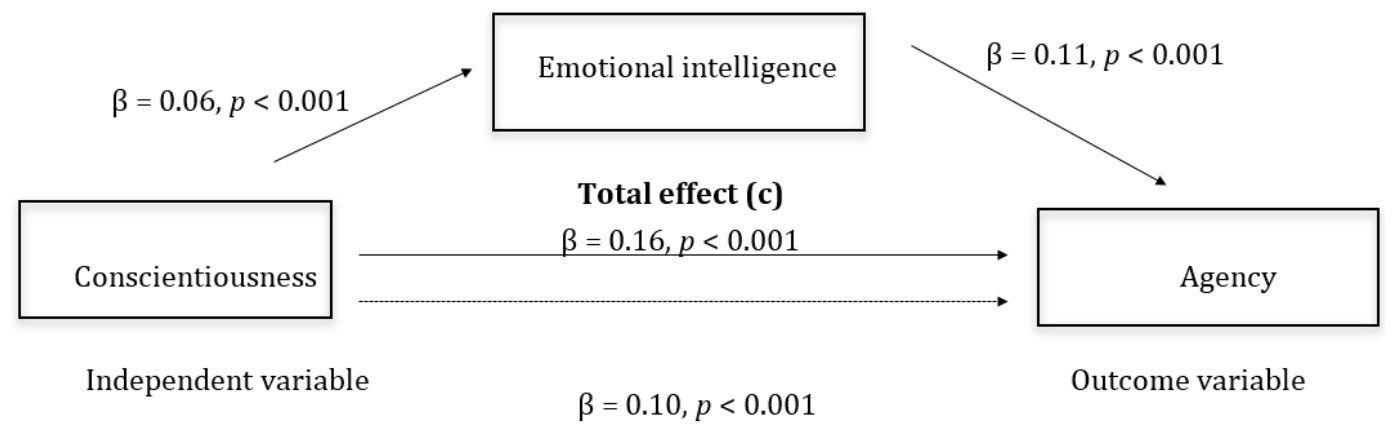

\section{Direct effect ( $\left(c^{\prime}\right)$}

Figure 9. Relationship between conscientiousness and agency dimension of hope with emotional intelligence as mediator. $R^{2}$ Mediator Effect Size $=0.10$.

Following the mediation analysis with pathways dimension of hope as the dependent variable was reported below.

In line with our hypothesis, extraversion exerted a significant positive indirect effect on pathways dimension of hope through emotional intelligence $(\beta=0.08, p<0.001)$. The biased-corrected bootstrapping confidence interval for the indirect effect did not contain zero, 95\% CI [0.04, 0.13]. After controlling for emotional intelligence, there was a significant positive direct effect of extraversion on pathways dimension of hope, $\beta=0.13, p<0.001$. The effect of the mediator was significant with an effect size of $11 \%$. The results are illustrated in Figure 10.

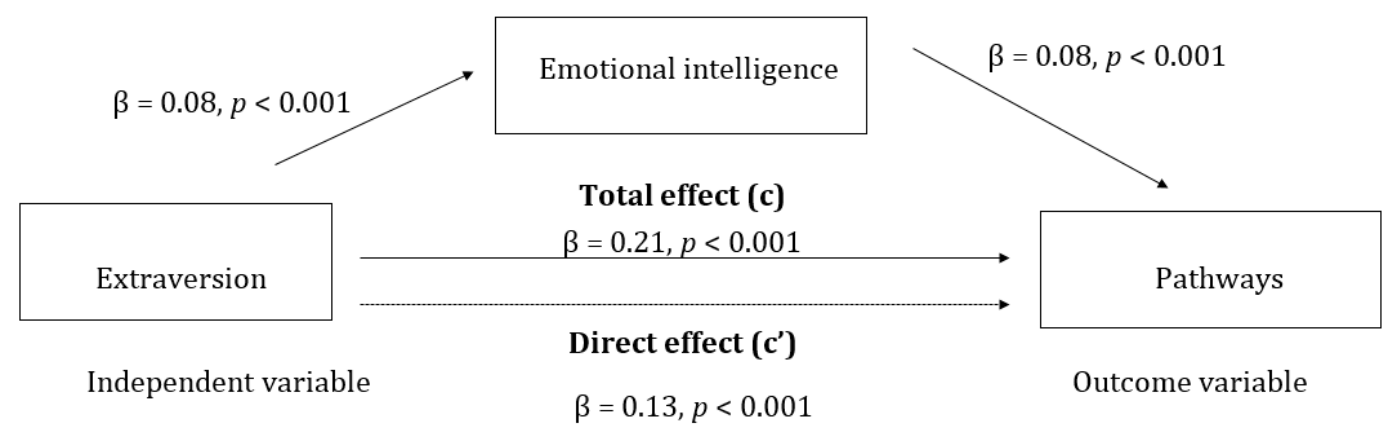

Figure 10. Relationship between extraversion and pathways dimension of hope with emotional intelligence as mediator. $R^{2}$ Mediator Effect Size $=0.11$.

Emotional stability exerted a significant positive indirect effect on the pathways dimension of hope through emotional intelligence $(\beta=0.07, p<0.001$ ). The biased-corrected bootstrapping confidence interval for the indirect effect did not contain zero, $95 \%$ CI $[0.05,0.11]$. After controlling for emotional intelligence, there was a significant positive direct effect of emotional stability on pathways dimension of hope, $\beta=0.04, p<0.05$. The effect of the mediator was significant with an effect size of $10 \%$. The results are illustrated in Figure 11.

Conscientiousness exerted a significant positive indirect effect on pathways dimension of hope through emotional intelligence ( $\beta=0.06, p<0.001$ ). The biased-corrected bootstrapping confidence interval for the indirect effect did not contain zero, $95 \%$ CI $[0.03,0.10]$. After controlling for emotional intelligence, there was a significant positive direct effect of conscientiousness on pathways dimension 
of hope, $\beta=0.04, p<0.05$. The effect of the mediator was significant with an effect size of $4 \%$. The results are illustrated in Figure 12.

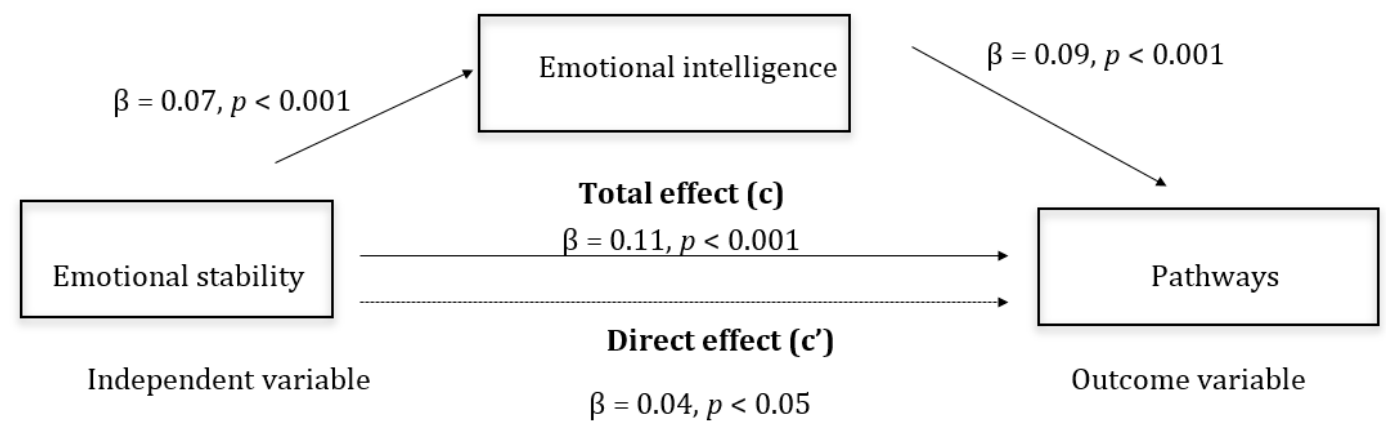

Figure 11. Relationship between emotional stability and pathways dimension of hope with emotional intelligence as mediator. $R^{2}$ Mediator Effect Size $=0.10$.

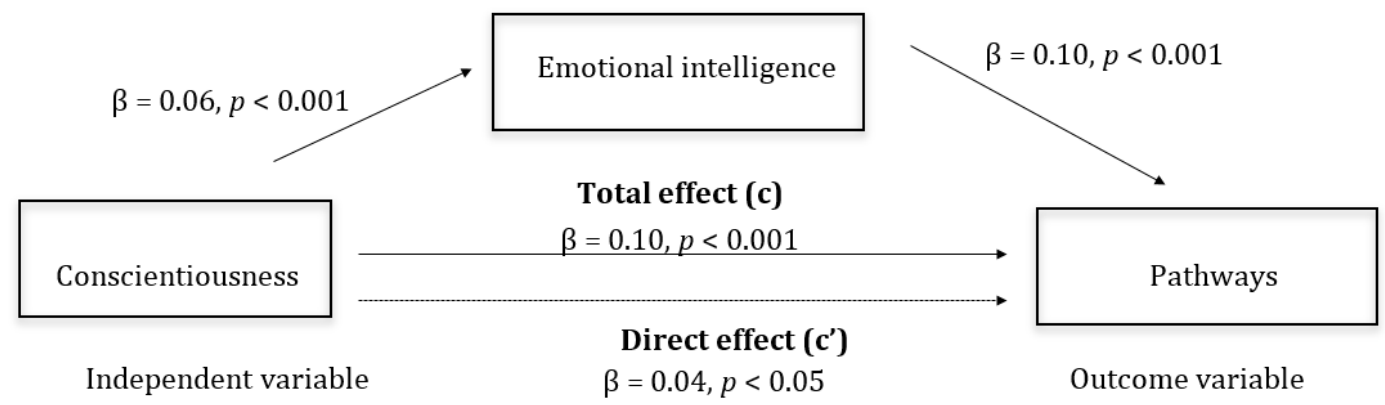

Figure 12. Relationship between emotional stability and hope with emotional intelligence as mediator. $R^{2}$ Mediator Effect Size $=0.04$.

\section{Discussion}

This study examined the contribution of emotional intelligence in mediating the relationship between personality traits and positive resources, such as optimism and hope with Italian workers. Hypothesis 1 stating that the contribution of emotional stability, agreeableness, and extraversion on optimism will be mediated by emotional intelligence was confirmed. Our results show that emotional intelligence can be regarded as a mediator of the contribution of these three personality traits on optimism. Thus, besides personality factors directly contributing to optimism, there is also a route via emotional intelligence: people high in emotional stability, agreeableness, and extraversion are not only more optimistic, but also higher in emotional intelligence, which, in turn, increases optimism. So, our results suggest the role of emotional intelligence as a mediator between these three personality traits and optimism defined as a more positive state of mind in terms of expectations that are related to social or material future [24]. More in detail, emotional intelligence in particular mediates the relationship between emotional stability and optimism, suggesting that emotional intelligence could contribute to manage emotions positively in relation to an optimistic state of mind regarding the future. Secondarily emotional intelligence mediates also the relationships between agreeableness and optimism and between extraversion and optimism, suggesting that positive self-evaluation of one's own emotional and social skills could be valuable regarding personality traits characterized by relations with others in relation to optimism.

Hypotheses 2 stated that the contribution of extraversion, emotional stability, and conscientiousness on hope will be mediated by emotional intelligence, which were confirmed as well. Therefore, besides these three personality factors directly contributing to hope, there is also a route via emotional intelligence: people high in extraversion, emotional stability, and conscientiousness have not only more hope, but are also higher in emotional intelligence, which, in turn, increases their hope. Our results thus highlight the role of emotional intelligence as a mediator between 
the personality traits of extraversion, emotional stability, conscientiousness, and hope in terms of goal-directed determination and planning of ways to meet goals [26,46]. Among these three different personality traits, emotional intelligence mediates in particular the relationship between extraversion and hope, suggesting that the perceived evaluation of one's own emotional and social skills seems to give its major contribution in relation to a personality trait characterized by relations with others and hope. Secondarily emotional intelligence mediates also the relationship between emotional stability and hope and also between conscientiousness and hope, suggesting a role of emotional intelligence both in managing emotion and in using perseverance and scrupulosity in relation to hope in terms of goal-directed determination and definition of paths to reach one's own goals [26,46].

Differences in personality traits that are associated with the two considered constructs (optimism and hope) also emerged in the mediating role of emotional intelligence. For optimism the higher relationship was with emotional stability whereas for hope the higher relationship was with extraversion. Emotional intelligence mediates more in the relationship between emotional stability and optimism and in the relationship between extraversion and hope. These results are in line with the literature, because optimism seems particularly related with aspects of emotion management [30-32,35,38], whereas hope seems more associated to aspects relative to extraversion as trust and enthusiasm towards others, ability to affirm one's own point of view, tendency to be actively engaged [36,37], and emotional intelligence emerged both as an antecedent of optimism [18] and as a predictor [22,23] of hope. The results showed also other specificities. In addition to the emotional stability, optimism was associated also with agreeableness and extraversion. In addition to extraversion, hope was associated also with emotional stability and conscientiousness. In all of these relationships, emotional intelligence acts as mediator giving a contribution to clarify the nature of these relationships: for optimism emotional intelligence seems secondly mediate more in relation to aspects connected to altruism, taking care of others, give emotional support [35], and also trust and enthusiasm towards others, whereas for hope to aspects relative to emotion management and also to scrupulosity and perseverance. Also, the third and the fourth hypotheses in relation to the two dimensions of hope were confirmed. On the basis of the results, emotional intelligence has a mediating function in the relationship between the personality traits of extraversion, emotional stability, conscientiousness and both the agency dimensions of hope (third hypothesis) and the pathways dimensions of hope (fourth hypothesis) in this study. In particular, the results showed that emotional intelligence has a mediating function more between extraversion and agency than between extraversion and pathways, suggesting that perceived emotional intelligence is able to give a contribution in particular in the relationship between extraversion as trust and enthusiasm towards others, ability to affirm one's own point of view, tendency to be actively engaged [36,37], and the energy to undertake one's own objectives and motivate oneself in times of difficulty (agency dimension) than the perceived capability to derive the paths to achieve the desired objectives (pathways dimension) [26,46], suggesting that emotional intelligence could contribute especially in relation to aspects that regard goal-directed determination. Anyway, emotional intelligence is able to give a contribution in terms of mediation between the three traits of personality (extraversion, emotional stability, conscientiousness) and both the two dimensions of agency and pathways of hope. Finally, it is possible to note that emotional intelligence mediates more the relationship between personality traits and optimism with respect to the relationship between personality traits and hope, suggesting that emotional intelligence could offer a particular contribution in promoting a more positive state of mind or attitude associated to expectations that are related to social or material future [24], so it is fundamental to better face the challenges of the 21st century. Regarding personality traits, emotional stability and extraversion were associated to both optimism and hope, whereas agreeableness was associated only with optimism and conscientiousness was associated only with hope, underlining the importance of emotions and impulse control and characteristics of dynamism and dominance both for optimism and hope and a specificity in terms of characteristics of cooperativeness and cordiality for optimism and of scrupulosity and 
perseverance for hope that also includes aspects relative to motivation and perception to be able to realize objective and pursue pathways.

Notwithstanding, the present study showed the mediating role of emotional intelligence in the relationship between personality traits and both optimism and hope in Italian workers, the following limitations of the study should be noted. The results of the present study are not generalizable since it was carried out on a group of Italian workers in the Tuscany region that is not fully representative of Italian reality. Future research should therefore expand the study to participants from different geographical areas and from different organizations. Further research is also needed with other groups (e.g., high school students and university students) and also conducted in other national contexts. Future research could also examine these relationships, when considering different trait emotional intelligence models, such, for example, also the Bar-On [15] model and also ability-based emotional intelligence model [14]. Since this is a first study on the mediation role of emotional intelligence in the relationships between personality traits and both optimism and hope, future research is needed to set one model, including all of the Big Five domains, emotional intelligence, and optimism (and/or hope), and also examining the different sub-domains of emotional intelligence as mediators.

Despite these limitations, the results add to the literature showing the mediating role of trait emotional intelligence in the relationships between personality traits and the positive resources as optimism and hope in the perspective of the psychology of sustainability and sustainable development [51-53].

\section{Conclusions}

Optimism and hope are positive resources that are key factors in facing the challenges of the post-modern scenario. Emotional intelligence can be considered as another important variable in this context and furthermore research has shown it can be increased through specific training [10,11], differently from personality traits that can be considered stable in the literature [12]. Emotional intelligence with its role of mediator in the relationships between personality traits and both optimism and hope could respond to the goal number eight (decent work and economic growth) of the seventeenth UNESCO Sustainable Goals. To promote decent work, it is important to enhance individual resources for coping and adapting to changes in the world of work [54]. It is thus essential to early promote positive resources strengthening trait emotional intelligence to better cope with changes, challenges, and continuous transitions [55] characterizing the liquid scenario of the world of work in the 21st century. In conclusion, if the results of the present study will be further confirmed in future research, trait emotional intelligence could be considered promising to early promote positive individual resources going beyond personality traits.

Author Contributions: Conceptualization, A.D.F., Methodology, A.D.F., L.P., A.G.; Investigation, A.D.F., O.B., C.B. and E.P.; Data curation, A.D.F., L.P., O.B.; Writing-Original Draft Preparation, A.D.F. Writing-Review \& Editing, A.D.F., L.P., A.G.; Supervision, A.D.F.

Funding: This research received no external funding.

Conflicts of Interest: The authors declare no conflict of interest.

\section{References}

1. Di Fabio, A.; Saklofske, D.H. Comparing ability and self-report trait emotional intelligence, fluid intelligence, and personality traits in career decision. Personal. Individ. Differ. 2014, 64, 174-178. [CrossRef]

2. Di Fabio, A.; Saklofske, D.H. Promoting individual resources: The challenge of trait emotional intelligence. Personal. Individ. Differ. 2014, 65, 19-23. [CrossRef]

3. Di Fabio, A.; Saklofske, D.H. The contributions of personality and emotional intelligence to resiliency. Personal. Individ. Differ. 2018, 123, 140-144. [CrossRef]

4. Di Fabio, A.; Kenny, M.E. Emotional intelligence and perceived social support among Italian high school students. J. Career Dev. 2012, 39, 461-475. [CrossRef] 
5. Di Fabio, A.; Kenny, M.E. The contribution of emotional intelligence to decisional styles among Italian high school students. J. Career Assess 2012, 20, 404-414. [CrossRef]

6. Di Fabio, A.; Kenny, M.E. The contributions of emotional intelligence and social support for adaptive career progress among Italian youth. J. Career Dev. 2015, 42, 48-59. [CrossRef]

7. Di Fabio, A.; Kenny, E.M. From decent work to decent lives: Positive Self and Relational Management (PS\&RM) in the twenty-first century. Front. Psychol. 2016, 7, 361. [CrossRef] [PubMed]

8. Di Fabio, A.; Kenny, M.E.; Claudius, M. Preventing distress and promoting psychological well-being in uncertain times through career management intervention. In The Cambridge Handbook of International Prevention Science; Israelashvili, M., Romano, J.L., Eds.; Cambridge University Press: Cambridge, UK, 2016; pp. 233-254. ISBN 9781107087972.

9. Di Fabio, A.; Kenny, M.E.; Minor, K. School-based research and practice in Italy. In Handbook of Positive Psychology in the Schools, 2nd ed.; Furlong, M.J., Gilman, R., Huebner, E.S., Eds.; Taylor and Francis, Routledge: New York, NY, USA, 2014; pp. 450-464. ISBN 978-0-415-62185-4.

10. Di Fabio, A.; Kenny, M.E. Promoting emotional intelligence and career decision making among Italian high school students. J. Career Assess 2011, 19, 21-34. [CrossRef]

11. Vesely, A.K.; Saklofske, D.H.; Nordstokke, D.W. EI training and pre-service teacher wellbeing. Personal. Individ. Differ. 2014, 65, 81-85. [CrossRef]

12. Costa, P.T.; McCrae, R.R. NEO PI-R Professional Manual; Psychological Assessment Resources: Odessa, FL, USA, 1992; ISBN 9789997924452.

13. Stough, C.; Saklofske, D.H.; Parker, J.D. Assessing Emotional Intelligence: Theory, Research, and Applications; Springer: New York, NY, USA, 2009; ISBN 978-0-387-88370-0.

14. Mayer, J.D.; Salovey, P. What is emotional intelligence? In Emotional Development and Emotional Intelligence: Educational Implications; Salovey, P., Sluyter, D., Eds.; Basic Books: New York, NY, USA, 1997; pp. 3-31.

15. Bar-On, R. The Emotional Intelligence Inventory (EQ-I): Technical Manual; Multi-Health Systems: Toronto, ON, Canada, 1997; ISBN 978-88-7466-497-9.

16. Petrides, K.V.; Furnham, A. Trait emotional intelligence: Psychometric investigation with reference to established trait taxonomies. Eur. J. Personal. 2001, 15, 425-428. [CrossRef]

17. Mayer, J.D.; Salovey, P.; Caruso, D.R. Selecting a measure of emotional intelligence: The case of ability scales. In The handbook of Emotional Intelligence; Bar-On, R., Parker, J.D., Eds.; Jossey Bass: San Francisco, CA, USA, 2000; pp. 320-342. ISBN 100787949841.

18. Augusto-Landa, J.M.; Pulido-Martos, M.; Lopez-Zafra, E. Does perceived emotional intelligence and optimism/pessimism predict psychological well-being? J. Happiness Stud. 2011, 12, 463-474. [CrossRef]

19. Extremera, N.; Durán, A.; Rey, L. Perceived emotional intelligence and dispositional optimism-pessimism: Analyzing their role in predicting psychological adjustment among adolescents. Personal. Individ. Differ. 2007, 42, 1069-1079. [CrossRef]

20. Mikolajczak, M.; Luminet, O.; Menil, C. Predicting resistance to stress: Incremental validity of trait emotional intelligence over alexithymia and optimism. Psicothema 2006, 18, 79-88. [PubMed]

21. Schutte, N.S.; Malouff, J.M.; Hall, L.E.; Haggerty, D.J.; Cooper, J.T.; Golden, C.J.; Dornheim, L. Development and validation of a measure of emotional intelligence. Personal. Individ. Difer. 1998, 25, 167-177. [CrossRef]

22. Batool, M.; Niazi, S.; Ghayas, S. Emotional intelligence as a predictor of sense of humor and hope among adults. J. Indian Acad. Appl. Psychol. 2014, 40, 270-278.

23. Saricam, H.; Celik, I.; Coşkun, L. The Relationship between Emotional Intelligence, Hope and Life Satisfaction in Preschool Preserves Teacher. Int. J. Res. Teach. Educ. 2015, 6, 1-9.

24. Scheier, M.F.; Carver, C.S. Optimism, coping, and health: assessment and implications of generalized outcome expectancies. Heath Psychol. 1985, 4, 219-247. [CrossRef]

25. Seligman, M.E.; Csikszentmihalyi, M. Positive psychology: An introduction. Am. Psychol. Assoc. 2000, 55, 5-14. [CrossRef]

26. Snyder, C.R. Hope theory: Rainbows in the mind. Psychol. Inq. 2002, 13, 249-275. [CrossRef]

27. Boland, A.; Cappeliez, P. Optimism and neuroticism as predictors of coping and adaptation in older women. Personal. Individ. Differ. 1997, 22, 909-919. [CrossRef]

28. Marshall, G.N.; Wortman, C.B.; Kusulas, J.W.; Hervig, L.K.; Vickers, R.R., Jr. Distinguishing optimism from pessimism: Relations to fundamental dimensions of mood and personality. J. Personal. Soc. Psychol. 1992, 62, 1067-1074. [CrossRef] 
29. Williams, D.G. Dispositional optimism, neuroticism, and extraversion. Personal. Individ. Differ. 1992, 13, 475-477. [CrossRef]

30. Ebert, S.A.; Tucker, D.C.; Roth, D.L. Psychological resistance factors as predictors of general health status and physical symptom reporting. Psychol. Health Med. 2002, 7, 363-375. [CrossRef]

31. Marshall, G.N.; Wortman, C.B.; Vickers, R.R.; Kusulas, J.W.; Hervig, L.K. The five-factor model of personality as a framework for personality-health research. J. Personal. Soc. Psychol. 1994, 67, 278-286. [CrossRef]

32. Milligan, M. Optimism and the five-factor model of personality, coping, and health behavior. Diss. Abstr. Int. 2003, 64, 5830 .

33. Sharpe, J.P.; Martin, N.R.; Roth, K.A. Optimism and the Big Five factors of personality: Beyond neuroticism and extraversion. Personal. Individ. Differ. 2011, 51, 946-951. [CrossRef]

34. Segerstrom, S.C.; Castañeda, J.O.; Spencer, T.E. Optimism effects on cellular immunity: testing the affective and persistence models. Personal. Individ. Differ. 2003, 35, 1615-1624. [CrossRef]

35. Bastianello, M.R.; Pacico, J.C.; Hutz, C.S. Optimism, self-esteem and personality: adaptation and validation of the Brazilian Version of the Revised Life Orientation Test (LOT-R). Psico-USF 2014, 19, 523-531. [CrossRef]

36. Halama, P. Hope as a mediator between personality traits and life satisfaction. Stud. Psychol. 2010, 52, 309-314.

37. Halama, P.; Dedova, M. Meaning in life and hope as predictors of positive mental health: do they explain residual variance not predicted by personality traits? Stud. Psychol. 2007, 49, 191-200.

38. Caprara, G.V.; Barbaranelli, C.; Borgogni, L. BFQ: Big Five Questionnaire, 2nd ed.; Giunti O.S.: Firenze, Italy, 1993; ISBN 9788809400672.

39. Spielberger, C.D.; Gorsuch, R.L.; Lushene, R.E. State-Trait Anxiety Inventory; Consulting Psychology Press: Palo Alto, CA, USA, 1968; ISBN 8809400933.

40. Wechsler, D. Manual for theWechsler Adult Intelligence Scale-Revised; The Psychological Corporation: New York, NY, USA, 1981; ISBN B0006YQQPS.

41. Petrides, K.V.; Furnham, A. The role of trait emotional intelligence in a gender-specific model of organizational variables. J. Appl. Soc. Psychol. 2006, 36, 552-569. [CrossRef]

42. Di Fabio, A.; Palazzeschi, L. Proprietà psicometriche del Trait Emotional Intelligence Questionnaire Short Form (TEIQue-SF) nel contesto italiano [Psychometric properties of the Trait Emotional Intelligence Questionnaire Short Form (TEIQue-SF) in the Italian context]. Couns. G. Ital. Ric. Appl. 2011, 4, 327-336.

43. Mayer, J.D.; Salovey, P.; Caruso, D.R. MSCEIT User's Manual; Multi-Health Systems: Toronto, ON, Canada, 2002.

44. Giannini, M.; Schuldberg, D.; Di Fabio, A.; Gargaro, D. Misurare l'ottimismo: Proprietà psicometriche della versione italiana del Life Orientation Test-Revised (LOT-R) [Measuring optimism: Psychometric properties of the Italian version of the Life Orientation Test-Revised (LOT-R)]. Couns. G. Ital. Ric. Appl. 2008, 1, 73-83. [CrossRef]

45. Rosenberg, M. Society and the Adolescent Self-Image; Princeton University Press: Princeton, NJ, USA, 1965; ISBN 13 978-0691649443.

46. Snyder, C.R.; Harris, C.; Anderson, J.R.; Holleran, S.A.; Irving, L.M.; Sigmon, S.T.; Gibb, J.; Langelle, C.; Harney, P. The will and the ways: Development and validation of an individual-differences measure of hope. J. Personal. Soc. Psychol. 1991, 60, 570-585. [CrossRef]

47. Rothwell, A.; Herbert, I.; Rothwell, F. Self-perceived employability: Construction and initial validation of a scale for university students. J. Voc. Behav. 2008, 73, 1-12. [CrossRef]

48. Betz, N.E.; Taylor, K.M. Manual for the Career Decision Making Self-Efficacy Scale (CDMSES) and CDMSES-Short Form; Unpublished Manuscript, The Ohio State University: Columbus, OH, USA, 2000.

49. Hayes, A.F. Introduction to Mediation, Moderation, and Conditional Process Analysis: A Regression-Based Approach; The Guilford Press: New York, NY, USA, 2013; ISBN 9781462534654.

50. Hayes, A.F. PROCESS: A Versatile Computational Tool for Observed Variable Mediation, Moderation, and Conditional Process Modeling [White Paper]. 2012. Available online: http://www.afhayes.com/public/ process2012.pdf (accessed on 1 March 2018).

51. Di Fabio, A. Positive Healthy Organizations: Promoting well-being, meaningfulness, and sustainability in organizations. Front. Psychol. 2017, 8, 1938. [CrossRef] [PubMed]

52. Di Fabio, A. The psychology of sustainability and sustainable development for well-being in organizations. Front. Psychol. 2017, 8, 1534. [CrossRef] [PubMed] 
53. Di Fabio, A.; Kenny, M.E. Promoting well-being: The contribution of emotional intelligence. Front. Psychol. 2016, 7, 1182. [CrossRef] [PubMed]

54. Blustein, D.L.; Kenny, M.E.; Di Fabio, A.; Guichard, J. Expanding the impact of the psychology of working: Engaging psychology in the struggle for decent work and human rights. J. Career Assess 2018. [CrossRef]

55. Di Fabio, A.; Bucci, O.; Gori, A. High Entrepreneurship, Leadership, and Professionalism (HELP): Towards an integrated, empirically based perspective. Front. Psychol. 2016, 7, 1842. [CrossRef] [PubMed] 